\title{
A Method for Designing Conforming Folding Propellers
}

\author{
Brandon L. Litherland, Michael D. Patterson†, Joseph M. Derlaga $\ddagger$ and Nicholas K. Borer ${ }^{\S}$ \\ NASA Langley Research Center, Hampton, VA, 23681, U.S.A.
}

\begin{abstract}
As the aviation vehicle design environment expands due to the influx of new technologies, new methods of conceptual design and modeling are required in order to meet the customer's needs. In the case of distributed electric propulsion (DEP), the use of highlift propellers upstream of the wing leading edge augments lift at low speeds enabling smaller wings with sufficient takeoff and landing performance. During cruise, however, these devices would normally contribute significant drag if left in a fixed or windmilling arrangement. Therefore, a design that stows the propeller blades is desirable. In this paper, we present a method for designing folding-blade configurations that conform to the nacelle surface when stowed. These folded designs maintain performance nearly identical to their straight, non-folding blade counterparts.
\end{abstract}

\section{Nomenclature}

$\begin{array}{ll}{[F]} & \text { Folded blade frame of reference } \\ {[T]} & \text { Transformation matrix of direction cosines. } \\ {[U]} & \text { Unfolded blade frame of reference } \\ \beta_{\text {drive }} & \text { Driving blade section twist angle } \\ \beta_{\text {local }} & \text { Local blade section twist angle } \\ \beta_{\text {rel }} & \text { Local blade section twist angle relative to the driving section } \\ \Delta V & \text { Velocity change } \\ \Phi & \text { Blade folding angle } \\ \boldsymbol{a} & \text { Blade hinge axis vector } \\ A_{\text {nac }} & \text { Nacelle cross-section area } \\ R & \text { Propeller radius } \\ r & \text { Local blade section radial distance from the propeller center } \\ r_{\mathrm{CG}} & \text { Blade center of mass radial location } \\ r_{\text {hinge }} & \text { Blade folding hinge radial location } \\ R_{\text {nac }} & \text { Local nacelle section radius } \\ x_{\text {nac }}(r) & \text { Local nacelle cross-section location aft of the nacelle datum } \\ x_{\text {prop }} & \text { Propeller distance aft of the nacelle datum }\end{array}$

\section{Introduction}

The X-57 Maxwell, NASA's next manned X-plane, will demonstrate technologies with the potential to drastically increase the energy efficiency of general aviation aircraft. The X-57 uses relatively small diameter, distributed, electrically-driven propellers, which are called "high-lift propellers" because they act as high-lift devices by accelerating the air over the wing. ${ }^{1}$ This flow acceleration enables lift augmentation at low speeds, enabling a more aerodynamically efficient wing designed for cruise performance rather than for takeoff and

*Aerospace Engineer, Aeronautics Systems Analysis Branch, 1 N. Dryden St. MS 442

${ }^{\dagger}$ Aerospace Engineer, Aeronautics Systems Analysis Branch, 1 N. Dryden St. MS 442, AIAA Member.

${ }^{\ddagger}$ Research Scientist, Computational AeroSciences Branch, 15 Langley Blvd. MS 128, AIAA Member.

$\S$ Aerospace Engineer, Aeronautics Systems Analysis Branch, 1 N. Dryden St. MS 442, AIAA Senior Member. 
landing. However, if these high-lift propellers are left to windmill in the freestream flow during cruise, significant drag is added to the aircraft that negates the benefits of the more cruise-efficient wing. In order to reduce cruise drag from the high-lift propeller system, a propeller design that is capable of smoothly folding against a nacelle is desired. Although only a single folding propeller design is required for the X-57's 12 high-lift propellers, a systematic method for blade folding was sought to enable the rapid generation of folding propeller designs in support of early-phase design studies.

Current examples of folding propeller applications in aviation include the Joby $\mathrm{S} 2^{2}$ and $\mathrm{S} 4,{ }^{3}$ NASA's LEAPTech Project, ${ }^{4}$ and NASA's GL-10 "Greased Lightning." ${ }^{5}$ Also, folding propellers are used extensively in powered gliders such as the Stemme S10, ${ }^{6}$ where the propeller blades are stowed within the nose of the fuselage, and the Alisport Silent 2 Electro, ${ }^{7}$ where the propeller blades fold back along the nose. More recently in the remotely operated aircraft market, folding propeller blades - e.g. the Graupner CAM folding propeller line ${ }^{8}$ - have gained popularity. Historically, folding propellers have been used for marine applications, specifically sailboat auxiliary propulsion, since the $1960 \mathrm{~s}^{9}{ }^{9}$

Several disadvantages of current folding blade approaches can be identified. For example, a disadvantage of using the trailing propeller or "pusher" arrangement typically seen in marine applications is that the folded blades are left to shed wakes that contribute to drag even when folded, albeit a smaller amount than when unfolded and exposed to freestream fluid. Some leading propeller or "tractor" propeller configurations with folding blades have been designed to conform to the nacelle or nose by adjusting the twist and chord distribution of the blade or by simply recessing the blade into the body. This strategy implies that conformity and not performance drives the design, which is undesirable. In the case of powered-glider folding-blade designs, the leading and trailing edges of the blade are often left protruding from the nacelle or nose - e.g., the Silent 2 Electro - which can result in low pressure regions leading to increased circulation between the body and blade during stowed-blade (unpowered) flight. Furthermore, exposure of excess surfaces by nonconformally recessing the blade into the body results in increased wetted area and cavities, which contribute to parasite drag. Although it is possible to completely stow the blades within the attached nacelle or fuselage - e.g., the Stemme S10 - the mechanism to accomplish this task is typically highly complex and therefore heavy. Additionally, the folding mechanism is much too large for use in the X-57 high-lift nacelles, which are significantly smaller in diameter than the fuselages of motor-gliders.

An improved folding method is desired for the X-57 high-lift propellers so that cruise drag can be reduced and the propeller performance is minimally impacted at relevant takeoff and landing conditions. This will ensure that the lift augmentation from the folding blades is effectively unchanged from the non-folding blades. To help maintain near-equivalent performance, a folding method that only translates the blade section in the rotating frame while maintaining the original chord and twist distribution is desired. In this way, the spinning local blade section remains unchanged relative to the incident flow. Furthermore, an ideal folding mechanism should be as mechanically simple as possible; therefore, it is also desirable to develop blades that can fold about a single degree of freedom hinge. Although the X-57 high-lift propellers are a use-case here, the method is applicable for most propeller designs and not necessarily limited to aeronautics.

In this paper, we present a systematic method to modify the design of a propeller blade so that it can be folded against an axisymmetric body. The benefits of the method proposed in this paper are:

1. there will be no appreciable loss in propeller performance between the folded design and its fixed-blade counterpart in relevant takeoff and landing conditions;

2. the mechanism for folding the blades is simple, moving about only a single axis;

3. the blades may be designed for performance rather than conformity; and

4. the method allows for the fitting of most propeller designs to an axisymmetric body.

We will also present an example application of the method to the X-57 high-lift propellers and the production, blade deployment testing, and operational testing of a full-scale high-lift nacelle prototype demonstrating the method's feasibility.

\section{Modifying Propellers for Folding}

The method presented in this section is capable of taking virtually any blade shape and modifying it to conform to an axisymmetric nacelle. However, certain blades will conform to the nacelle more smoothly than 
others. It is assumed here that all blades of the propeller are of uniform design and that the nacelle onto which the propeller will fold is axisymmetric. Theoretically, the methods presented below could be applied to an asymmetric nacelle by treating the folding of each individual propeller blade separately.

The specifics of solving the folding problem were determined to be:

1. solving for the transformation matrix that correctly orients the folded blades to calculate the folding axis and angle;

2. determining the conformed nacelle surface shape;

3. finding the proper hinge radial location for the desired hinge size;

4. solving for the blade rake and skew distribution that conforms the blade to the nacelle; and

5. determining the desired blade recess depth.

In the subsections that follow, each of these steps is discussed in detail.

\section{A. Determining Blade Hinge Axis and Folding Angle}

To avoid the addition of complex, mechanical parts that add significant mass and failure opportunities to the propellers, a single degree of freedom hinge is chosen for the blade folding mechanism. Determining the hinge axis and angle that would result in the desired transformation from the unfolded to the folded frame, while also properly orienting the blade along the nacelle, is not straightforward. To accomplish this task, an Eulerian transformation matrix of direction cosines is selected for changing orientation about a fixed point. Therefore, the first step of the method is to determine a transformation matrix resulting in the hinge axis and folding angle for the blade.

For a chosen blade cross-section, there will be a single point on the nacelle where the local twist is tangent to the nacelle surface. Although the modification calculations can be made about any point on the airfoil, it is desirable to maintain symmetry about the control point so that recessing the blade does not create an excessively deep blade pocket or leave a portion of the blade exposed that favors the leading or trailing blade edges. Therefore, the fixed point is taken as the half-chord location at the root of the blade, which means that the airfoil sections become chord-symmetric about a blade-radial centerline, simplifying the modifications.

For a true transformation of blade orientation, the initial and final blade orientation frames are needed to define the transformation between them. Therefore, a frame of reference for the blade itself is defined according to the blade (radial), rake, and skew directions, as shown in Figure 1. The positive blade direction is defined as the direction perpendicular to the airfoil plane, passing through the propeller center of rotation, and pointing toward the blade tip. The positive rake direction is the direction perpendicular to the local chord line in the airfoil plane and pointing away from the airfoil lower surface. The positive skew direction is the direction parallel to the local chord line in the airfoil plane and pointing toward the airfoil trailing edge. Figure 2 shows a comparison of the unfolded and folded blade frames as defined in the modeling XYZ coordinate system where $\mathrm{X}$ is aft-positive, $\mathrm{Y}$ is right-positive, and $\mathrm{Z}$ is up-positive.

The blade reference frames can be defined by Eqs. 1 and 2, where $\beta_{\text {drive }}$ is the local blade section twist driving the rotation, $[F]$ is the folded frame, and $[U]$ is the unfolded frame. The driving section should be chosen first as all other blade sections are modified relative to this cross-section. For this case, the unfolded Blâde is parallel to $\hat{Y}$ and the folded Blâde is parallel to $\hat{X}$ - i.e., straight aft - such that the blade airfoil cross-sections and the nacelle cross-sections are parallel. By choosing a driving local blade section, the designer is able to control how the blade rake and skew is distributed.

$$
\begin{aligned}
& {[F]=\begin{array}{c}
\hat{X} \\
\hat{Y} \\
\hat{Z}
\end{array}\left[\begin{array}{ccc}
\text { Blâde } & \text { Râke } & \text { Skew } \\
1 & 0 & 0 \\
0 & -1 & 0 \\
0 & 0 & 1
\end{array}\right]} \\
& {[U]=\begin{array}{c}
\hat{X} \\
\hat{Y} \\
\hat{Z}
\end{array}\left[\begin{array}{ccc}
\text { Blâde } & \text { Râke } & \text { Skew } \\
0 & \cos \left(\beta_{\text {drive }}\right) & \sin \left(\beta_{\text {drive }}\right) \\
1 & 0 & 0 \\
0 & -\sin \left(\beta_{\text {drive }}\right) & \cos \left(\beta_{\text {drive }}\right)
\end{array}\right]}
\end{aligned}
$$




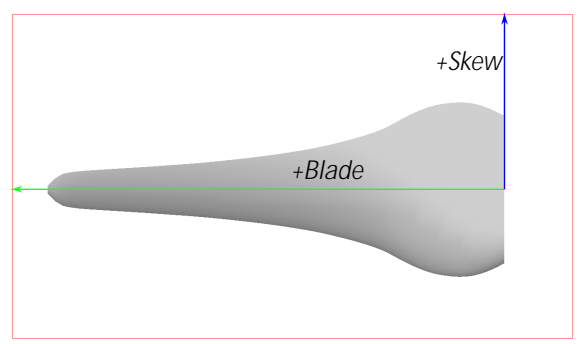

(a) Blade top view

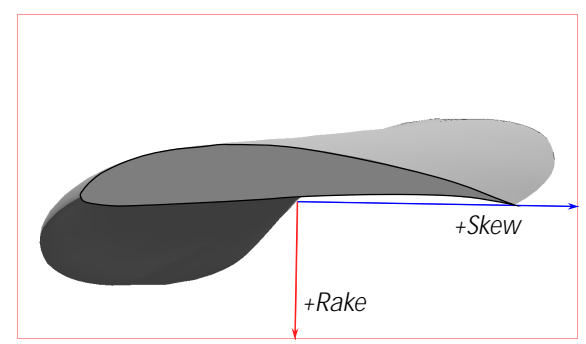

(b) Blade root view

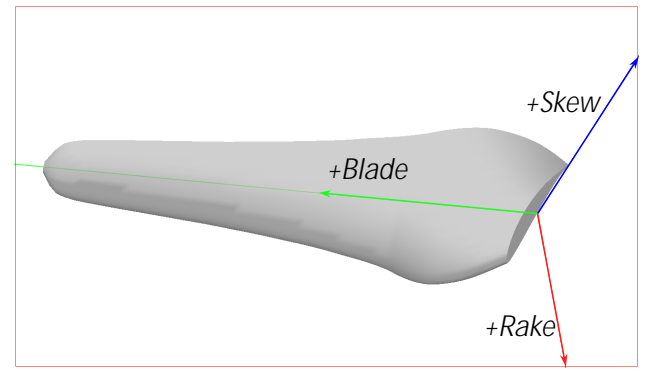

(c) Blade perspective view

Figure 1. Blade reference frames with the blade root as the driving section.

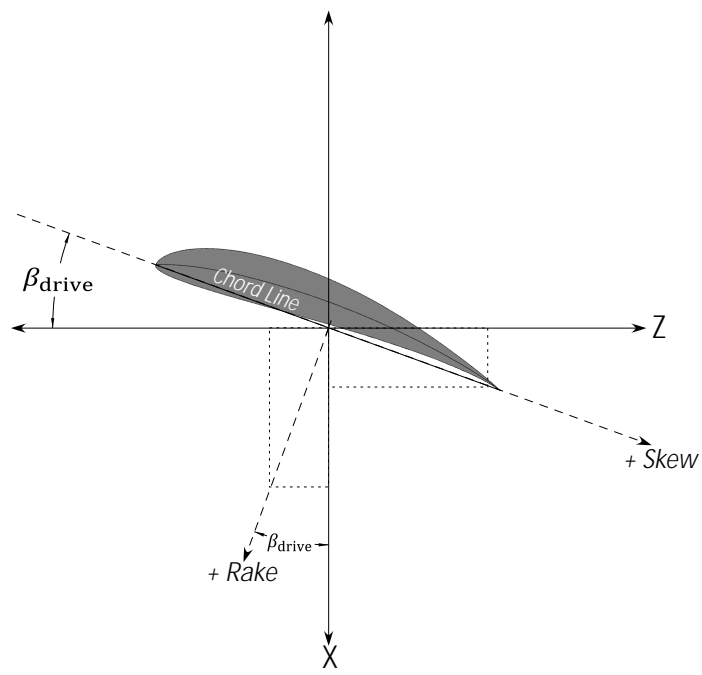

(a) Unfolded frame

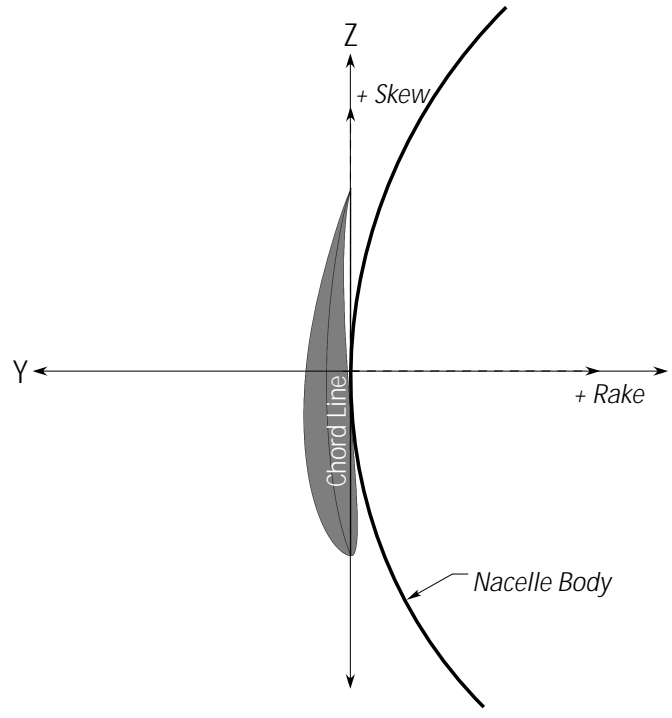

(b) Folded frame

Figure 2. A comparison between the unfolded and folded blade frames in XYZ coordinate space.

As an example, if it is desired that the folded root section have a chord-normal vector, equivalent to - Rakke, parallel to $\hat{Y}$, then the driving section is the root and therefore the root twist is used for the folding calculations. If it is desired for the $r=0.5 R$ section, where $R$ is the propeller radius, to have a folded normal parallel to $\hat{Y}$, then this is the driving section. This driving twist angle is also used later for finding the relative twist of the radial blade stations. It is advantageous to choose the driving section corresponding to the radial location of the blade center of mass such that $\beta_{\text {drive }}=\beta\left(r_{\mathrm{CG}}\right)$. In doing so, the blade center of mass is more closely aligned to the unfolded Blade, which reduces the magnitude of the moments generated about the blade hinge. Figure 3 provides an illustration of the blade normal vector concept. 


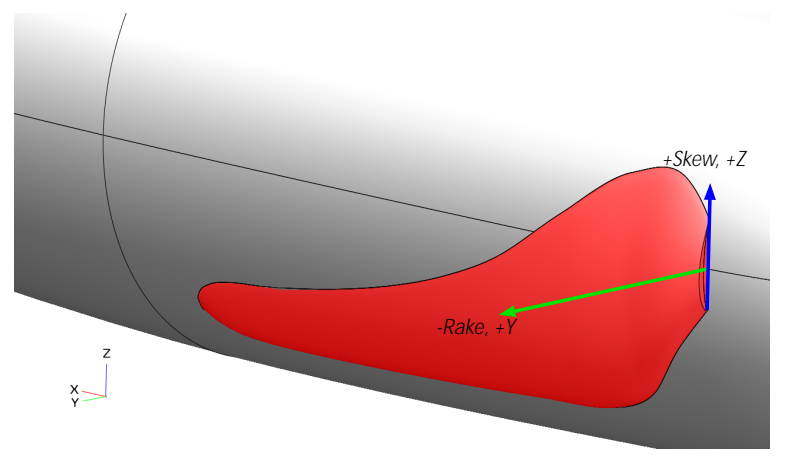

(a) Normal $\hat{Y}$ at the root

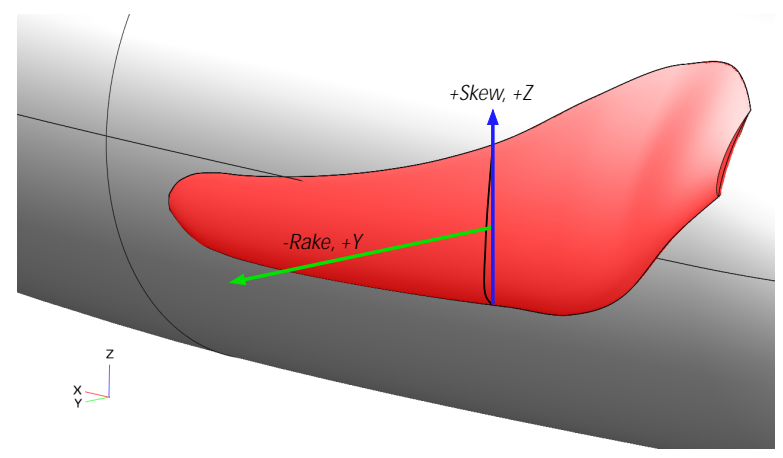

(b) Normal $\hat{Y}$ at the $0.5 R$ station

Figure 3. The blade radial location desired to have a folded normal of $\hat{Y}$ (green) drives the folding equations.

The Eulerian transformation matrix, $[T]$, relating the two reference frames, $[F]=[T][U]$, is a matrix of direction cosines of the Euler angles $\psi, \theta$, and $\phi$ shown in Eq. 3. Without knowing any of these angles in advance, solving for $\psi, \theta$, and $\phi$ becomes iterative and is not direct.

$$
[T]=\left[\begin{array}{ccc}
\cos \psi \cos \theta & \sin \psi \cos \theta & -\sin \theta \\
-\sin \psi \cos \phi+\cos \psi \sin \theta \sin \phi & \cos \psi \cos \phi+\sin \psi \sin \theta \sin \phi & \cos \theta \sin \phi \\
\sin \psi \sin \phi+\cos \psi \sin \theta \cos \phi & -\cos \psi \sin \phi+\sin \psi \sin \theta \cos \phi & \cos \theta \cos \phi
\end{array}\right]
$$

However, according to Euler's Theorem: ${ }^{10}$

The most general displacement of a rigid body with one point fixed is equivalent to a single rotation about some axis though that point.

Therefore, by using axis-angle transformation theory, ${ }^{10}$ the blade hinge axis vector, $\boldsymbol{a}=\left\{a_{\mathrm{x}}, a_{\mathrm{y}}, a_{\mathrm{z}}\right\}$, and folding angle, $\Phi$, can be found using the entries of $[T]$ rather than the cosine functions of $\psi, \theta$, and $\phi$ that define it. Solving for $[T]$ becomes simple due to each frame being an orthogonal matrix, where the matrix inverse is equal to its tranpose, as shown in Eq. 4, and the axis-angle solution for the transformation matrix is defined according to Eqs. 5 and $6 .^{\text {a }}$

$$
\begin{gathered}
{[T]=\left[\begin{array}{lll}
T_{11} & T_{12} & T_{13} \\
T_{21} & T_{22} & T_{23} \\
T_{31} & T_{32} & T_{33}
\end{array}\right]=[F][U]^{-1}=[F][U]^{T}} \\
\Phi=\arccos \left\{\frac{T_{11}+T_{22}+T_{33}-1}{2}\right\}=\arccos \left\{\frac{\operatorname{trace}[T]-1}{2}\right\} \\
\boldsymbol{a}=\left\{\frac{T_{23}-T_{32}}{2 \sin \Phi}, \frac{T_{31}-T_{13}}{2 \sin \Phi}, \frac{T_{12}-T_{21}}{2 \sin \Phi}\right\}
\end{gathered}
$$

It is important to note that the axis-angle transformation is an orientation change and not a physical rotation of the body. Rotating the frame about the fixed body by angle $\Phi$ is equivalent to rotating the body in a fixed frame by angle $-\Phi$ or reversing the rotation axis. This is the physical rotation angle implemented in the folding operation.

\section{B. Conforming the Blades to the Attached Nacelle}

To conform the attached propeller to the desired body shape, the physical geometry of the blade must be altered. The method for modifying the propeller design for folding comes from the assumption that changing the rake and skew distribution along the blade should not appreciably affect propeller performance. According to blade element momentum (BEM) theory, ${ }^{11}$ the thrust of a blade can be expressed as the sum

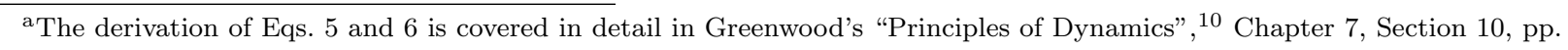
$341-344$ 
of the thrust generated by a series of two-dimensional airfoils along the blade radius. This implies that the only relevant parameters are the local velocity, local chord, and local angle of attack for a particular blade section, assuming that the airfoil distribution is known. While effects such as tip losses can affect the overall performance, the rake and skew of the local sections should have little effect on performance. Figure 4 illustrates that these adjustments only translate the airfoil section in the airfoil plane for a given radial location and therefore do not affect local chord or local angle of attack. Adjusting the local rake and skew should not significantly alter the aerodynamic properties of the 2-D airfoil blade section. Any performance losses are expected to be the results of 3-D effects, however these effects are assumed to be minimal. More detail on the blade performance is presented in Section III. Under this assumption, we are able to determine the appropriate translation - i.e., rake and skew - of the blade section relative to the body in the folded frame of reference without adversely affecting the unfolded performance.

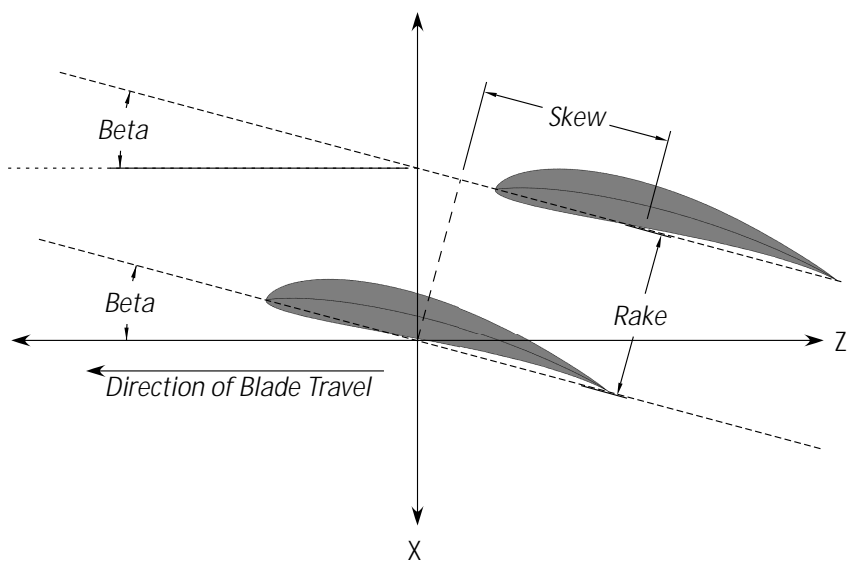

Figure 4. Visualization of rake and skew at a 2-D airfoil section. Direction of blade travel corresponds to the rotational travel of the propeller.

The blade section reference point should be the half-chord location on the airfoil as symmetry about this point simplifies the modification equations as discussed in Section II.A. Adjustments to the rake and skew of each section are found using this location and the local shape of the nacelle in the folded frame. This method assumes that the shape of the nacelle is known. For example, the local shape may be found by taking lateral slices of the geometry or by a predefined spline of the nacelle shape.

Figure 5 shows the relative translation of the airfoil section through adjusting the local rake and skew in order to place the chord line tangent to the nacelle without changing local twist. In this image, $r_{\text {hinge }}$ refers to the blade hinge radial location, $R_{\text {nac }}$ is the local nacelle radius, and $\beta_{\text {rel }}$ is the local blade section twist relative to the driving section twist, $\beta_{\text {rel }}=\beta_{\text {local }}-\beta_{\text {drive }}$. This process gives a reference location for making rake adjustments to set the blade recess depth.

Examining the dimensions in Figure 5, we see that the rake and skew distances can be solved from simple geometry using Eqs. 7 and 8.

$$
\begin{gathered}
\text { Skew }=r_{\text {hinge }} * \sin \left(\beta_{\text {rel }}\right) \\
\text { Rake }=r_{\text {hinge }} * \cos \left(\beta_{\text {rel }}\right)-R_{\text {nac }}
\end{gathered}
$$




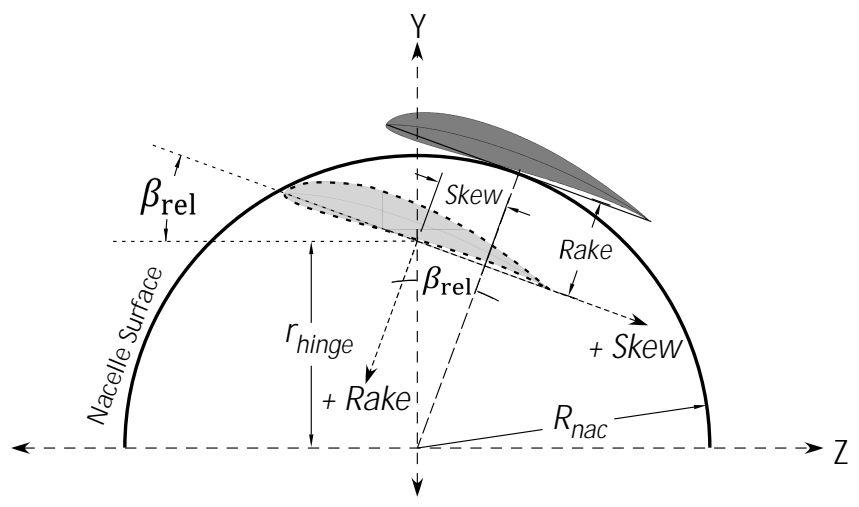

Figure 5. Two-dimensional visualization of the rake and skew modifications that place the airfoil chord line tangent to the nacelle surface at a specific radial station.

Further adjustment of the rake parameter may be necessary for proper conformity. By using the airfoil characteristics such as camber and thickness-to-chord ratio, the designer is able to place the airfoil section such that the any portion of the airfoil - e.g., top, bottom, mid-line, or leading and trailing edges - can be fitted to the nacelle surface profile. For example, if the intent is to match the leading and trailing edges of the propeller blade to the nacelle as shown in Figure 6, then the rake equation becomes:

$$
\text { Rake }=r_{\text {hinge }} * \cos \left(\beta_{\text {rel }}\right)-\sqrt{R_{\text {nac }}^{2}-\frac{C^{2}}{4}}
$$

The location of the hinge center, or fixed folding point, is largely up to the designer. However, to limit the amount of rake and skew needed to conform the blade to the nacelle, the hinge is placed as close to the nacelle surface as feasible while keeping the intended physical dimensions of the hinge within the body.

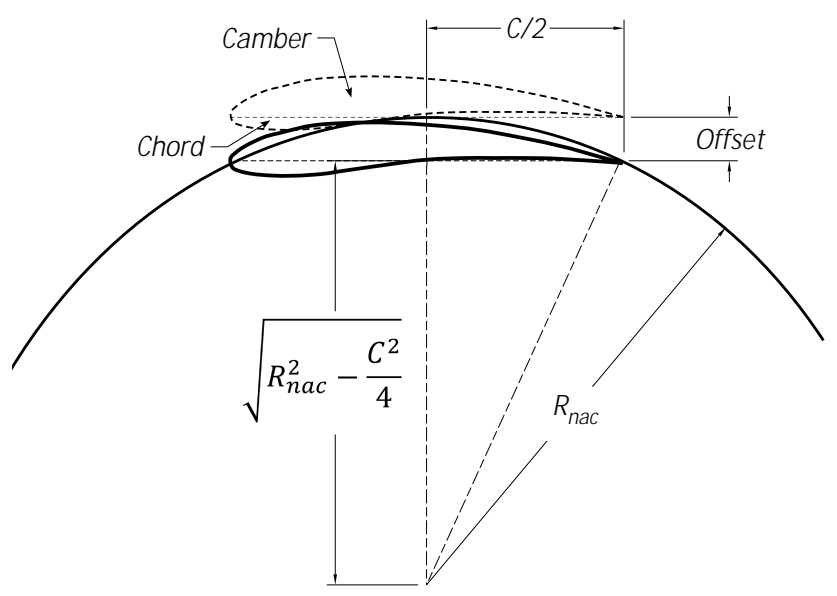

Figure 6. Visualization of the required rake modification to place the leading and trailing edges of the local airfoil section at the nacelle surface from a case where the chord line is tangent to the nacelle surface at the airfoil half-chord.

Mapping the locations of the folded blade to the nacelle cross-sections in order to determine the parameters for rake and skew calculations can be performed using a simple correction to the propeller distance aft of the nacelle datum. Figure 7 illustrates the need for the correction which is described in Eq. 10, where $x_{\text {nac }}(r)$ is the nacelle cross-section location aft of the nacelle datum, $x_{\text {prop }}$ is the propeller distance aft of 
nacelle datum, $r$ is the propeller blade cross-section radial location, and $r_{\text {hinge }}$ is the hinge radial location (presumed to be a $\hat{Y}$ distance).

$$
x_{\text {nac }}(r)=x_{\text {prop }}+\left(r-r_{\text {hinge }}\right)
$$

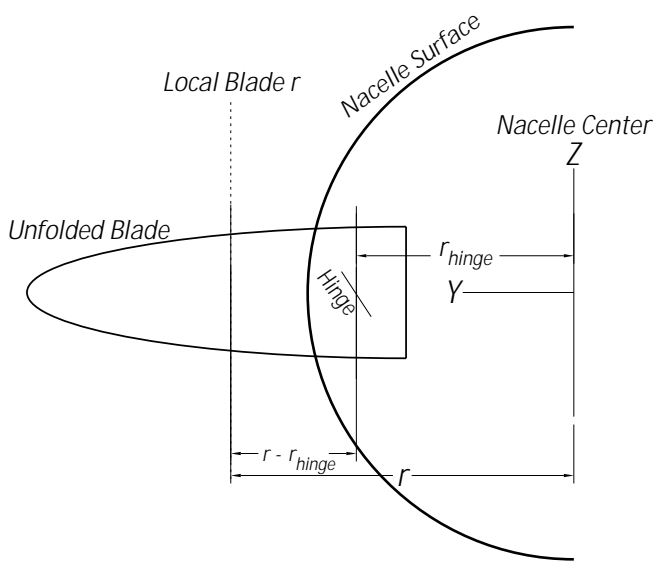

(a) Front view

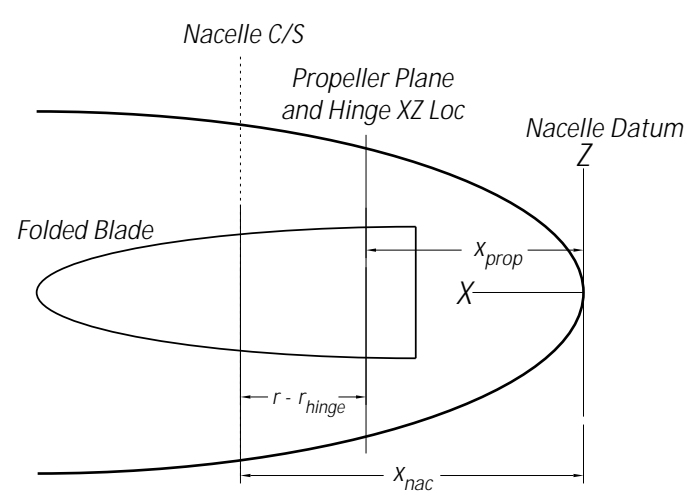

(b) Side view

Figure 7. Relating the nacelle cross-section to the local folded blade section is performed by correcting the propeller distance with the hinge radial location.

\section{Modeling the Folding Blade and Nacelle Geometry}

Initial modeling and inspection of the folding method was implemented in the parametric geometry design environment Open Vehicle Sketch Pad (OpenVSP). ${ }^{12}$ Within OpenVSP, a standalone "Prop" component generates propellers based on typical blade parameters such as propeller diameter and the radial distribution of chord and twist along the blade. Furthermore, folding blade action can be modeled using three folding angles and a fold location. In OpenVSP, the hinge location, $r_{\text {hinge }}$, is set by radial, axial, and offset distances normalized to blade radius, where radial is along the blade axis, axial is normal to the blade rotation plane, and offset is normal to the radial direction in the blade plane. In the example presented in this paper, only the radial distance is altered.

Using OpenVSP as a design tool allows the results of the folding method to be modeled in 3-D space. For example, the angle, azimuth, and elevation parameters are the three angles defining blade folding motion. Angle determines the physical rotation angle about the hinge axis while azimuth and elevation determine the orientation of the folding axis about the hinge position. Figure 8 illustrates the definition of azimuth and elevation in OpenVSP. In OpenVSP, the folding axis is oriented in the negative $\hat{Z}$ direction by default according to the previous XYZ coordinate definition from section II.A. A positive rotation about this axis results in a directly aftward fold. Recall that the calculated axis-angle transformation is by definition an orientation change and so to perform a physical rotation of the body in a fixed frame, either the angle, $\Phi$, or the axis, $\boldsymbol{a}$, must be reversed. Therefore, to keep the folding angle positive - i.e., positive fold angle moves the blade lower surface toward the nacelle - the blade folding axis, $\boldsymbol{a}$, is reversed for this example. 


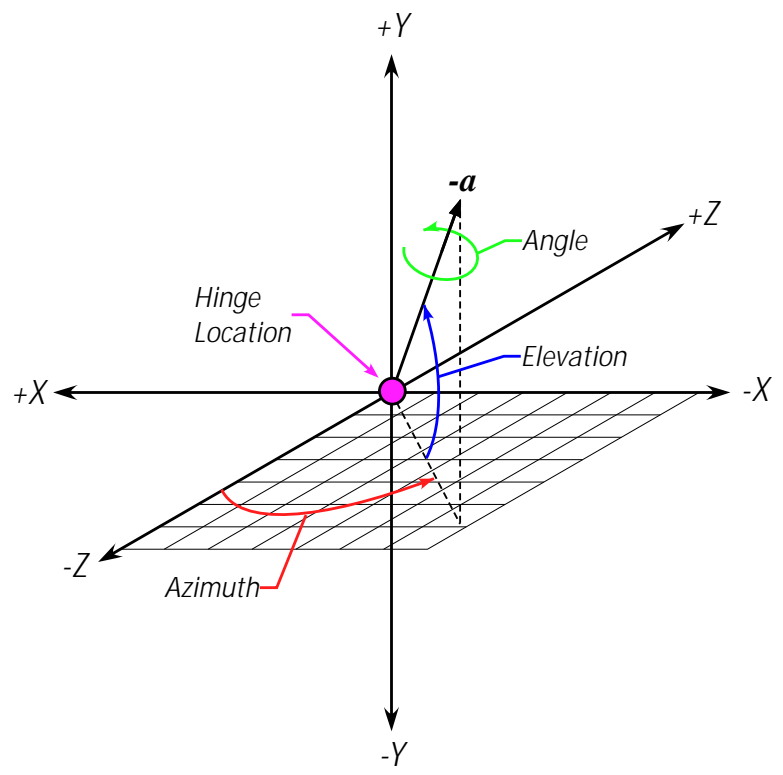

Figure 8. OpenVSP defines the folding axis using a hinge location and two angles, azimuth and elevation.

Azimuth and elevation can be calculated using Eqs. 11 and 12 and the values for $a_{\mathrm{x}}, a_{\mathrm{y}}$, and $a_{\mathrm{z}}$ which are determined from Eq. 6. Angle is equal to $\Phi$ from Eq. 5 .

$$
\begin{aligned}
& \text { Azimuth }=\arctan \left\{\frac{-a_{\mathrm{x}}}{-a_{\mathrm{z}}}\right\} \\
& \text { Elevation }=\arcsin \left\{\frac{-a_{\mathrm{y}}}{\|\boldsymbol{a}\|}\right\}
\end{aligned}
$$

Having found all of the necessary parameters for the folding blade rotation and placement, the rake and skew are calculated from the nacelle shape. Using OpenVSP's Planar Slice operation, which determines the area of each of a number of prescribed slices, the radius of the axisymmetric nacelle at each location is found assuming that each cross-section is circular - i.e., $A_{\text {nac }}(x)=\pi R_{\text {nac }}^{2}(x)$ where $R_{\text {nac }}(x)$ is the nacelle radius and $A_{\text {nac }}(x)$ is the area of the nacelle slice at location $x$.

Repeating the calculations and then entering the results into OpenVSP for all blade cross-sections leads to a successful model generation where the blade conforms to the nacelle surface as shown in Figure 9. Initially, this was done by manually entering the information for each section's blade parameters, which required a significant amount of time and effort. Currently, the results from the method calculations can be entered as vectors in an OpenVSP script that automatically generates the folding-blade component for a given nacelle shape. For the X-57 high-lift nacelle, the blade leading and trailing edge matching method from Eq. 9 was used. Observation of the folded and unfolded configurations suggested that a modification should be made to fully recess the blade root into the nacelle, which would improve the transition between the nacelle and blade surfaces. Burying the root section into the nacelle and smoothing this transition prevents the formation of stagnant flow regions at the blade root-nacelle intersection and reduces drag. Figure 10 shows the root correction using skew adjustment. 


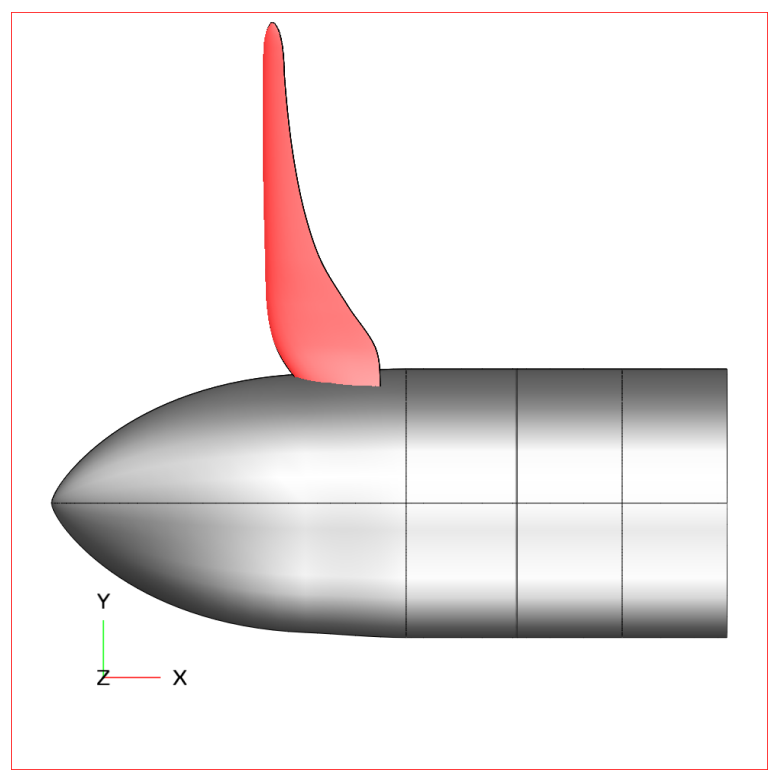

(a) Top view - unfolded

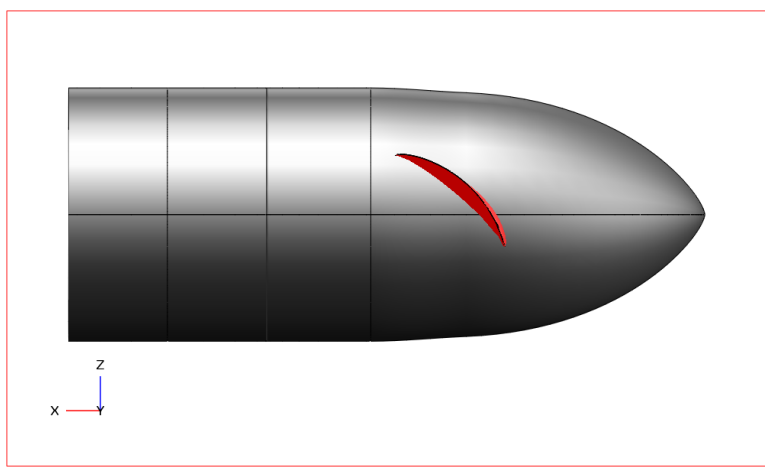

(c) Side view - unfolded

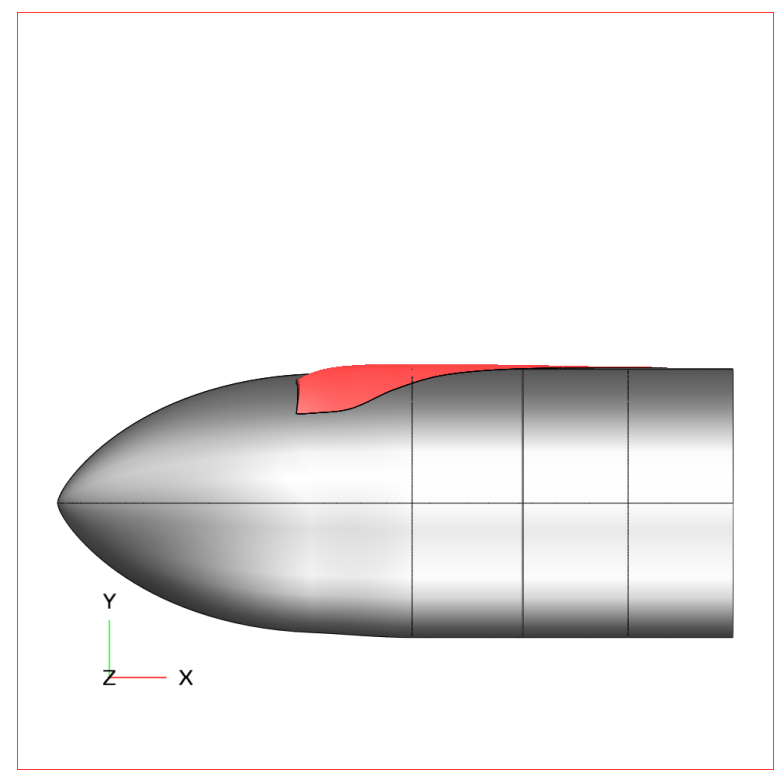

(b) Top view - folded

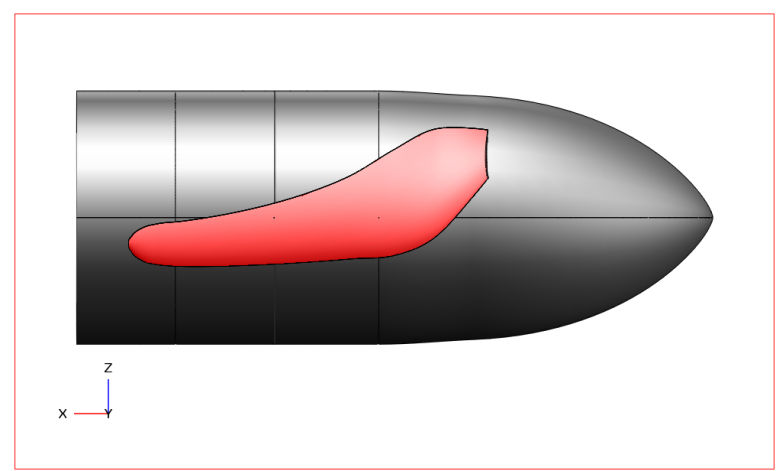

(d) Side view - folded

Figure 9. The folded blade was observed to conform to the nacelle surface as expected using blade leading and trailing edge surface matching from Eq. 9.

Once a satisfactory design was established in OpenVSP the component parameters were used as a reference for generating a higher-fidelity geometry with the PTC Creo Parametric ${ }^{\mathrm{TM}} 3.0$ (Creo 3) CAD (Computer-Aided Design) package. Reference datums were placed at each blade cross-section location and then the local chord, twist, rake, and skew were used to define the shape of the splined airfoil points. Once each cross-section was appropriately represented, the solid blade was generated by blending, or lofting, the sections together. 


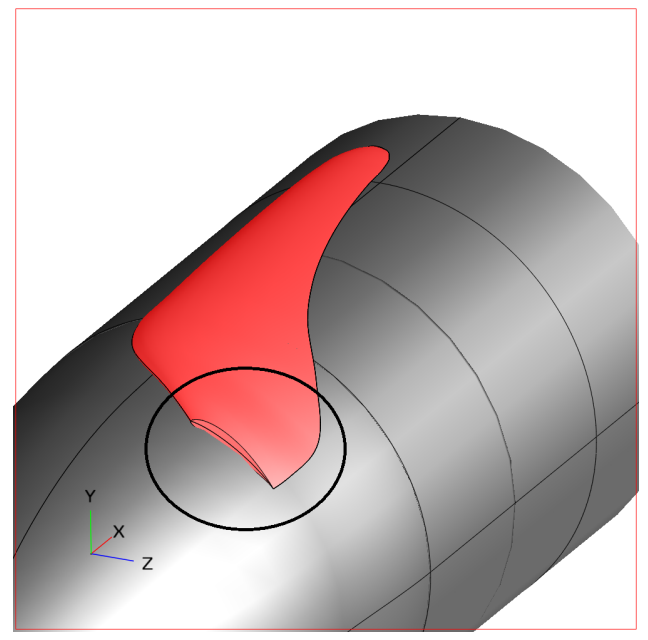

(a) Blade root exposed

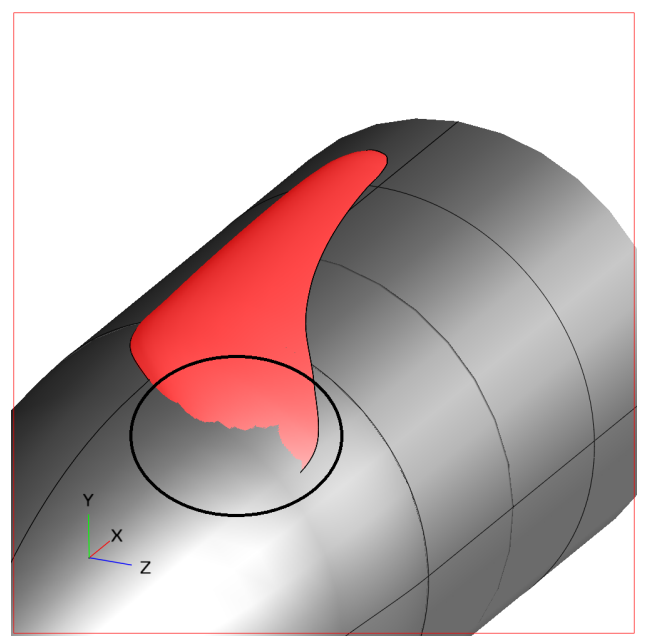

(b) Blade root recessed

Figure 10. The surface transition between the nacelle and blade can be smoothed by recessing the blade root into the nacelle.

Additional representative components for the high-lift nacelle were defined and then assembled in Creo 3 to generate a mock-up model of the high-lift nacelle assembly. A few examples of these components are the spinner, motor fins, tail cone, and propeller hub. This CAD model allowed for the observation of the folding-blade motion and interaction by enabling the manipulation of the components in 3-D space subject to spatially or mechanically defined constraints. Due to the simplified nature of the high-lift nacelle assembly, the propeller hub was designed to capture the intent of the hinge without heavy emphasis on the structural requirements for an X-57 production propeller. Figure 11(a) shows the propeller hub arms through the blade cutout. The necessity of an additional spinner cutout arose from the simple attachment of a hinge arm to the blade lower surface as illustrated in Figure 11. Each of the component cutouts in the mock-up assembly were accomplished by performing a component cut and blade projection extrusion in Creo 3 assembly mode. Once all of the components had been defined, cut, and assembled in the CAD model, each part was exported as stereolithography data for import into additive manufacturing slicing software to build a physical prototype of the folding blade high-lift nacelle.

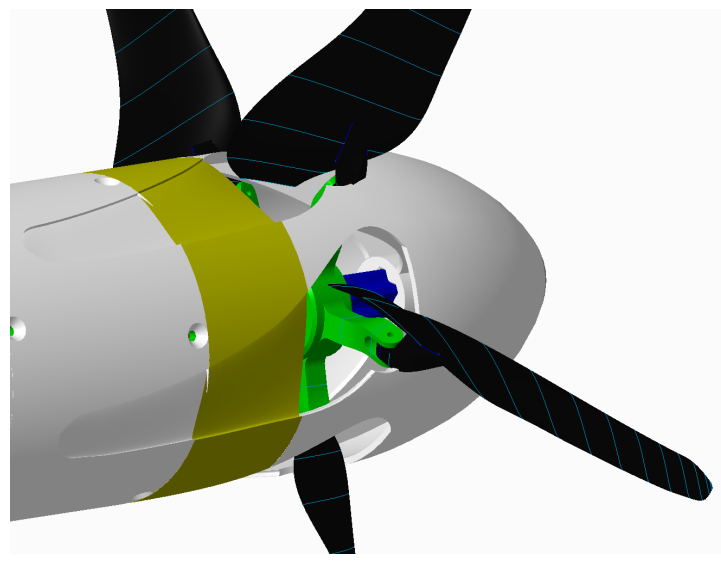

(a) CAD model showing folding blade cutouts for the spinner, motor fins, and aft nacelle section

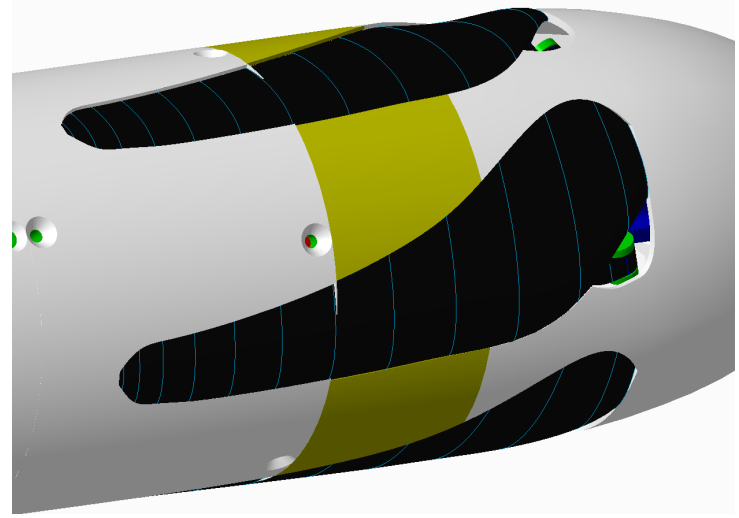

(b) CAD model showing the blades in their folded state

Figure 11. CAD representation of the high-lift nacelle and folding blades. 


\section{Folding Blade Performance}

Initial X-57 non-folding high-lift propellers were designed following the method presented in Ref. 13 so that at the desired stall speed of 58 knots (calibrated airspeed) and propeller speed of $4549 \mathrm{rpm}(450 \mathrm{ft} / \mathrm{s} \mathrm{tip}$ speed) the aircraft would produce $3,300 \mathrm{lb}$ of lift $-10 \%$ more than the projected weight of the vehicle. This lift margin was included in the propeller design to account for potential losses of blade performance from modifications for folding and to account for potential vehicle weight increases. Figure 12 shows a geometric comparison between the non-folding and folding designs. Note that in this use-case, a small section of the folding blade near the root has slightly shorter chord distribution. This modification was made to remove blade material directly forward of the hinge, which lessened the amount of material removed from the nacelle. Much of this section is within or very near to the nacelle during operation and this modification was not expected to have a major effect on blade performance.

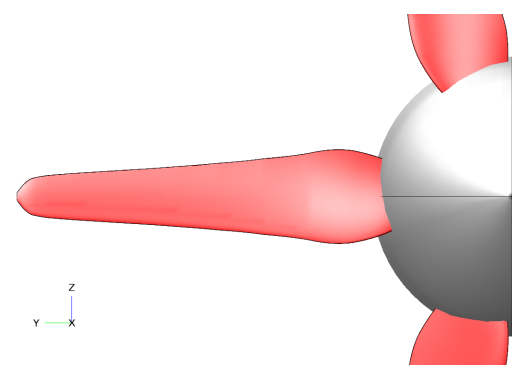

(a) Front view, non-folding blades

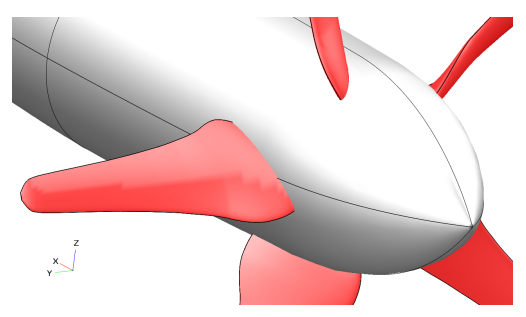

(c) Perspective view, non-folding blades

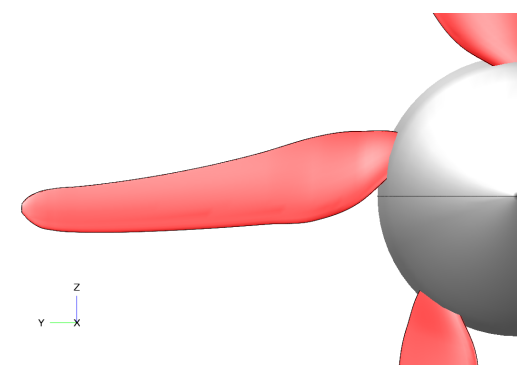

(b) Front view, folding blades

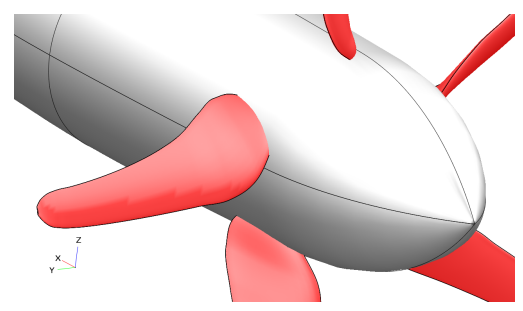

(d) Perspective view, folding blades

Figure 12. Geometric comparison between the unmodified and modified X-57 high-lift propeller blades.

The performance of the original non-folding propeller and its folding-blade counterpart were evaluated with OVERFLOW (OVERset grid FLOW solver), a structured, overset grid, Reynolds Averaged NavierStokes, computational fluid dynamics (CFD) flow solver developed at NASA. ${ }^{14,15}$ This examination compared the folded and non-folded blade thrust and velocity profiles with the blades operating at $4549 \mathrm{rpm}$ with a 58 knot freestream velocity. Based on the assumptions of the method, the performance of the folded blade was expected to relatively close to that of the non-folded blade. A fifth-order WENO5M (Weighted Essentially Non-Oscillatory) method ${ }^{16}$ with HLLE++ (Harten, Lax, van Leer and Einfeldt) flux scheme ${ }^{17}$ was used to calculate inviscid flux contributions and second-order central differences were used to approximate the viscous flux. A k- $\omega$ SST-RC-QCR2000 (rotation correction with quadratic constitutive relationship) turbulence model ${ }^{18,19}$ coupled with the Langtry-Menter CFX-v-1.1 transition model, ${ }^{20}$ despite not being Galilean invariant, was used to maintain commonality between all studies performed for the X-57 project. Dual time stepping with 25 subiterations and a physical step size corresponding to $1^{\circ}$ of rigid body rotation were used to predict the time accurate flow field, with at least eight revolutions of travel being simulated. Forces and moments were then averaged over the final revolution. In these simulations, the propeller and nacelle were run in isolation - i.e., without an X-57 pylon or wing.

Since the lift augmentation from the propellers should be tied primarily to the slipstream velocity profile, the induced velocities from the folding and non-folding propellers were compared. The circumferentiallyaveraged velocity profiles at four downstream distances are shown in Figure 13. As can be seen in this figure, there is little difference between the velocity profiles of the folding and non-folding blade propellers at each of these downstream locations. This is strong evidence that the lift augmentation of these propellers will be similar. 
Table 1 shows the performance of the folding and non-folding propellers as predicted by the OVERFLOW simulations. Differences of less than $4 \%$ in power and torque were observed between the folding and nonfolding designs. Additionally, differences of approximately $2 \%$ in thrust and in average axial velocity were predicted due to tip loss effects and the modifications to the folded-blade root chord, which indicates that there is very little performance loss from modifying the propeller for folding. Since thrust, torque, power, and the average induced velocity are all reduced compared to the non-folding blade design, a slight increase to the propeller RPM can be made to equate any one of these parameters with the baseline.

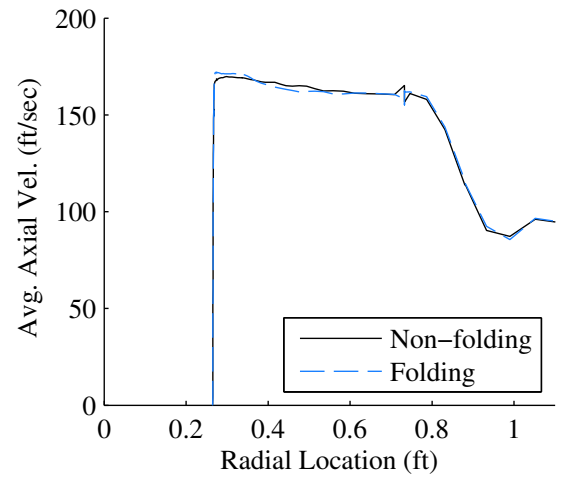

(a) downstream distance of $0.75 \mathrm{ft}$

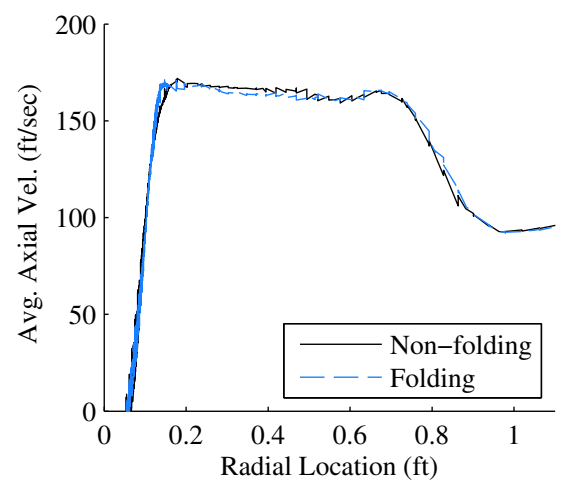

(c) downstream distance of $2.6 \mathrm{ft}$

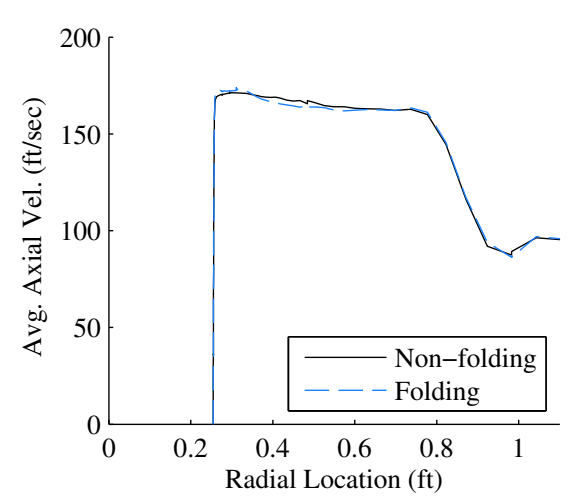

(b) downstream distance of $0.97 \mathrm{ft}$

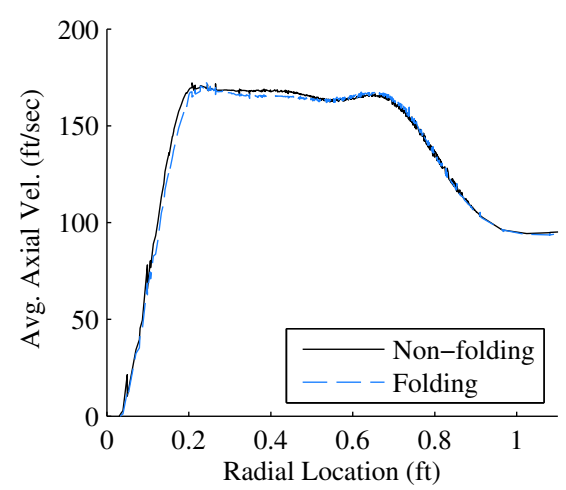

(d) downstream distance of $3.3 \mathrm{ft}$

Figure 13. Circumferentially averaged axial velocity distributions at four locations downstream of the propeller disk.

Ultimately, it is desired that the high-lift propellers produce sufficient lift augmentation on the full aircraft wing to enable flight below the stall speed of the unblown wing. Consequently, additional OVERFLOW simulations and/or experimental tests of the folding high-lift propellers installed onto the wing should be made to verify that the lift augmentation is sufficient. Such simulations or experiments have not been made to-date, but it is likely that the folding propellers will provide the required lift augmentation for flight because:

1. the original non-folding propellers were designed to provide a $10 \%$ lift margin over the required maximum lift coefficient for the full aircraft;

2. CFD simulations with actuator disks using the non-folding propeller parameters indicated that maximum lift coefficients of over 4.0 (and close to the 10\% design margin) could be achieved even though a maximum $C_{\mathrm{L}}$ of 3.95 is required to meet the desired stall speed; and

3. the performance of the folding blades is degraded only slightly as compared to the non-folding blades (as described above). 
Table 1. Comparison of Predicted Propeller Performance for the Non-Folding and Folding-Blade Designs.

\begin{tabular}{l|ccc}
\hline \hline & Original Blade & New Blade & \% Change \\
\hline Thrust (N) & 222 & 217 & $-2.3 \%$ \\
Power (kW) & 10.3 & 9.91 & $-3.8 \%$ \\
Torque (N-m) & 21.5 & 20.8 & $-3.3 \%$ \\
Avg Axial $\Delta V(\mathrm{~m} / \mathrm{s})$ & 16.8 & 16.5 & $-1.6 \%$ \\
\hline \hline
\end{tabular}

\section{Prototype Assembly and Testing}

In addition to the performance analyses, a folding-blade prototype high-lift nacelle was created from CAD model files using additive manufacturing to test the physical operation and dynamics of the assembled model. This prototype was used to identify problem areas or "show-stoppers" during assembly or blade deployment and also to conduct a low-speed operational test of the blade spin.

Testing of the folding blade geometries and their interaction with the high-lift nacelle was performed by 3-D printing the CAD exported stereolithography (STL) data and assembling the parts. Each exported STL file was interpreted as printing path data for two printers at the NASA Langley Research Center LarkWorks MakerSpace printing lab. Given the relatively large size of the parts compared to normal desktop 3-D printing applications, a re:3D Gigabot ${ }^{\mathrm{TM}}$ printer was used for most of the work, supplemented by a LulzBot Taz- $6^{\mathrm{TM}}$ desktop printer. For example, the longest part produced was the 18 inch long tail cone whereas the LulzBot Taz- 6 has a longest dimension of 11 inches. All of the filaments used to produce the parts were polylactide (PLA) of various color and manufacturer.

The final assembly successfully integrated each component as a stand-in for their respective real-world counterparts and demonstrated the operation of the folding action of the individual blades. Figure 14 shows the collection of assembly components, Figure 15(a) shows the fully assembled prototype, and Figure 15(b) shows a detailed view of the conformal blade profile in the folded configuration.

The X-57 deployment method rotates the folded blades out of their stowed position and extends the blades as the rotation speed increases. The blade cutout in the high-lift nacelle body was initially designed to have a blunt edge around the perimeter of the cut. However, it was determined early in the design process that the blades would not be able to spin freely from the folded configuration if they contacted this blunt surface. To address this concern, additional material was chosen to be removed from the cutout leading edge once the parts were printed to provide a ramped region for blade contact during spin-up. Figure 16 illustrates a comparison between the blunt and ramped cutout edge and Figure 17 shows perspectives on the final, shaped cutout.

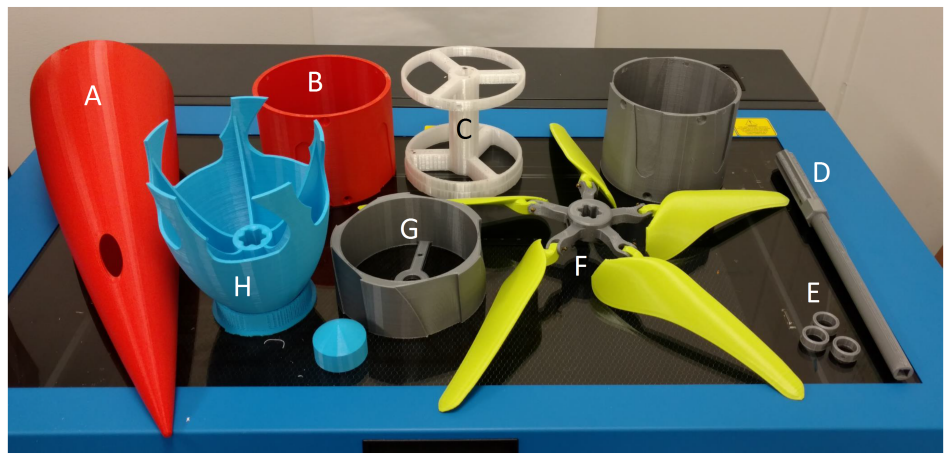

Figure 14. Displayed collection of the prototype parts. Pictured are the tail cone (A), aft nacelle body (B), internal structure (C), drive shaft (D), locking collars (E), propeller and hub assembly (F), motor cooling block $(\mathrm{G})$, and the spinner $(\mathrm{H})$. 

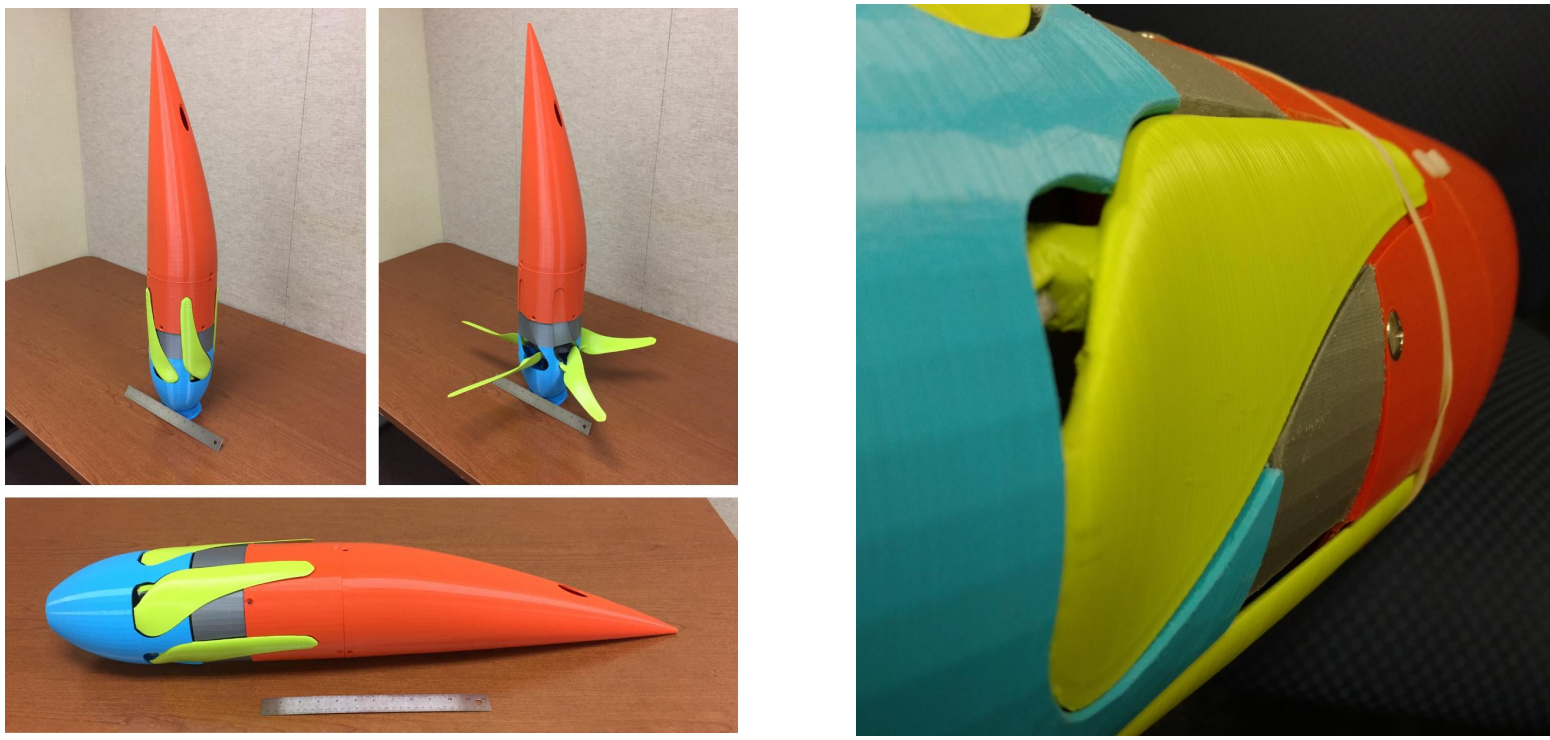

(a) Assembled prototype

(b) Conformal blade profile

Figure 15. Final prototype assembly aligning the blade cutout regions for each component. A 12 in ruler is shown for scale.

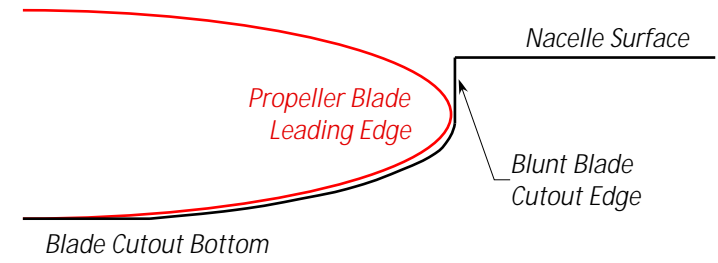

(a) Blunt blade cutout edge

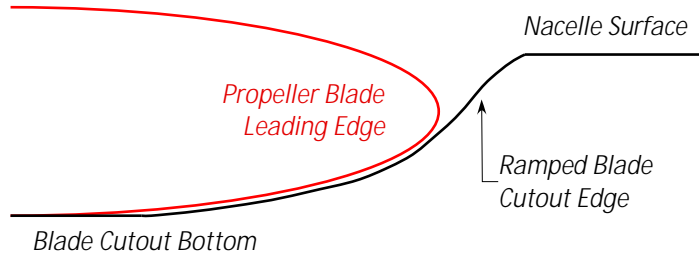

(b) Ramped blade cutout edge

Figure 16. Ramping the blade cutout allows the blade to transition out of the blade recess. 


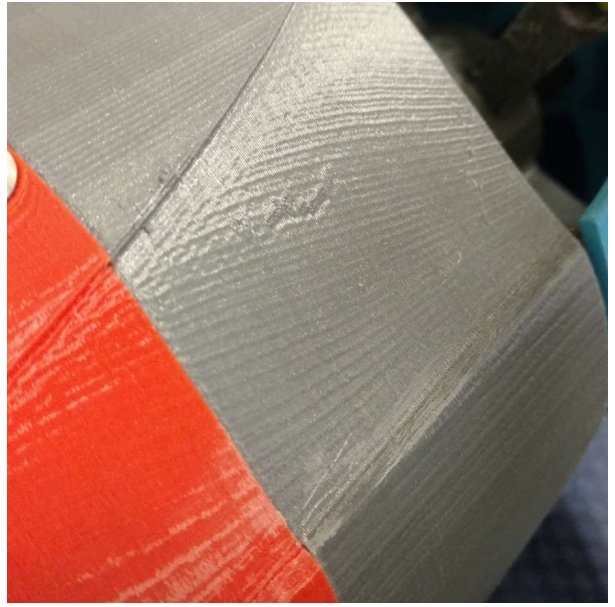

(a) Rear view of ramped cutout

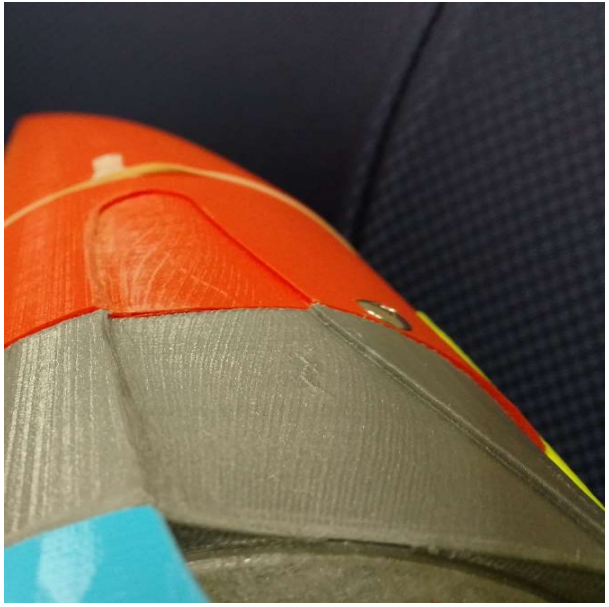

(b) Front view of ramped cutout

Figure 17. Final prototype assembly parts with ramped blade cutouts.

A low-speed spin test was performed to observe the blade unfolding and spinning operations. A small, $18 \mathrm{~V}$ electric motor was connected to the propeller drive shaft and then the power was gradually increased to simulate the actual blade spin-up operation of the X-57 high-lift motors. To reduce the risk to the prototype or personnel, the test speed was maintained under 400 revolutions per minute. Several tests were video captured at 30 frames per second for real-time recordings and 120 frames per second for slow-motion recordings. Playback of the slow-motion video at 30 frames per second - i.e., $1 / 4$ of real-time speed - revealed that the propeller blades did not fully unfold while spinning as initially expected. At first, this was thought to be an effect of the reduced thrust at the low test speed. However, upon inspection of the mass properties of the model, a slight misalignment between the blade center of mass and the propeller rotation plane was identified. Approximating the moments generated about the hinge axis for this use-case revealed that the blade center of mass distance from the plane of propeller rotation generated a moment almost sixty times greater than that of the thrust on the blade. Therefore, for any blade speed the blade center of mass would seek the smallest distance to the propeller rotation plane thereby minimizing its potential energy. Figure 18 shows a comparison of the laboratory spin test and the spinning blade minimum potential energy position as modeled in OpenVSP, where the axes are roughly aligned to the high-lift nacelle aft section wall and the blade rotation plane. In each image, the red circle corresponds to the approximate location of the center of mass. The blade-incident air velocity is only reduced by about $0.6 \%$ in this case but the reduction in the projected propeller diameter causes a roughly $2.5 \%$ loss in thrust in addition to the small performance losses from tip effects and the shortened root chord. Although the effects of these losses compounded are still small overall, any avoidable drop in performance should be mitigated. To correct this behavior, a future design could incorporate a small counterweight at the blade hinge arm to net a zero moment balance about the blade folding axis. 


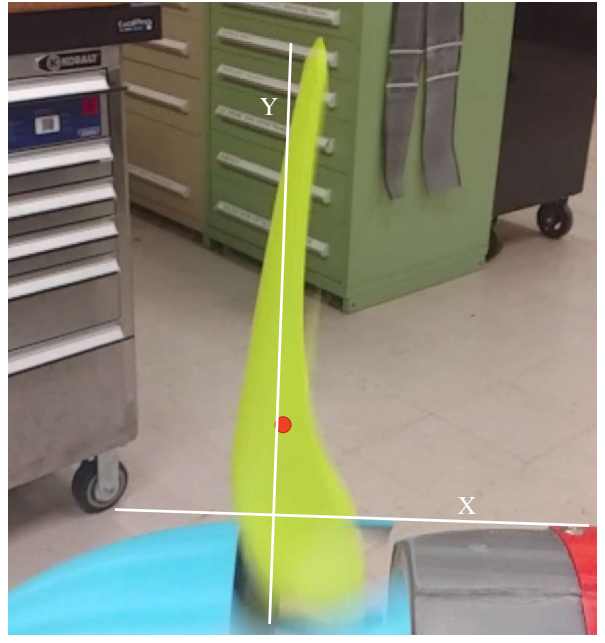

(a) Laboratory spin test

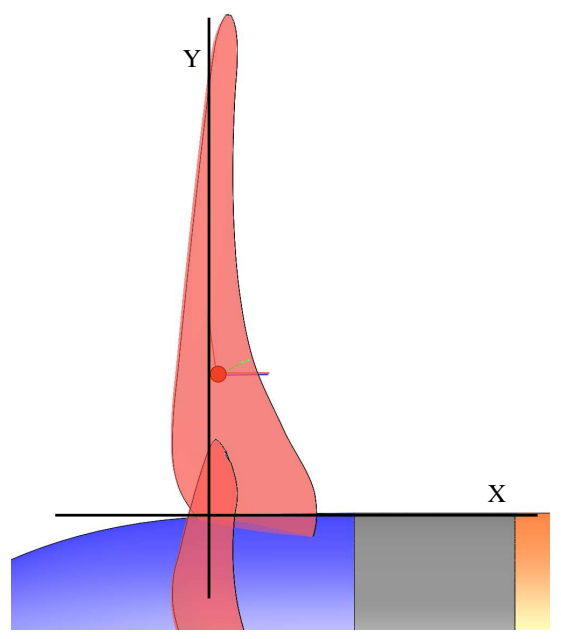

(b) OpenVSP model

Figure 18. A comparison between the laboratory spin test and the VSP model showing similar behavior driven by the blade center of mass location.

\section{Conclusions and Future Work}

In response to the requirements of the $\mathrm{X}-57$ high-lift propeller system, the method described in this paper produces nacelle-conforming, folding propeller blades that enable reduced drag during cruise. The computational performance analyses and prototype assembly demonstrate that the folding blade design method is likely feasible for and reduces the risk of real-world application. And, although the method does not solve every problem of propeller blade integration for final production, it serves as a basis for blade designs that produce drag reduction benefits in stowed-blade flight regimes.

The approximate $2 \%$ reduction in average axial velocity and thrust and $4 \%$ reduction in power and torque show that the method is capable of producing conformal propellers with performance very near to that of a non-folding baseline. An investigation into the folding propeller thrust at the same power as the non-folding baseline, rather than matching the rotational speed, would provide additional insight into the folding blade performance. The expectation is that such a comparison would further illustrate the performance match between the two designs.

The method improves on current folding propeller examples by manipulating an existing propeller blade designed for a specific type of performance. In this way, the blade can be designed for a desired velocity profile, maximum thrust, or minimum induced losses and still be modified for folding along the nacelle. For example, the X-57 high-lift propeller blades were designed to have a relatively constant velocity profile over the blade radius to support wing lift augmentation. The folded version of this blade is shown to have a velocity profile nearly identical to the non-folding baseline. Furthermore, since the method in this paper is systematic and therefore repeatable for a variety of nacelle and propeller configurations, it lends itself readily to design process automation thus saving valuable time.

To improve the overall applicability, accuracy, and speed of the method, future work will include:

1. adapting the method for asymmetric nacelle shapes;

2. automating the design process using baseline propeller geometry;

3. conducting further study on folding-blade performance comparisons; and

4. performing experiments with physical models to verify the computational performance results. 


\section{References}

${ }^{1}$ Borer, N. K., Patterson, M. D., Viken, J. K., Moore, M. D., Bevirt, J., Stoll, A. M., and Gibson, A. R., "Design and Performance of the NASA SCEPTOR Distributed Electric Propulsion Flight Demonstrator," 16th AIAA Aviation Technology, Integration, and Operations Conference, AIAA Aviation, American Institute of Aeronautics and Astronautics, June 2016, AIAA 2016-3920.

${ }^{2}$ Stoll, A. M., Stilson, E. V., Bevirt, J., and Pei, P. P., "Conceptual Design of the Joby S2 Electric VTOL PAV," 14 th AIAA Aviation Technology, Integration, and Operations Conference, AIAA Aviation, American Institute of Aeronautics and Astronautics, June 2014, AIAA 2014-2407.

${ }^{3}$ Stoll, A., "Analysis and Full Scale Testing of the Joby S4 Propulsion System," Transformative Vertical Flight Workshop, 3 August 2015, http://nari.arc.nasa.gov/sites/default/files/attachments/Stoll-TVFW-Aug2015.pdf, accessed 18 Oct 2016.

${ }^{4}$ Stoll, A. M., "Comparison of CFD and Experimental Results of the LEAPTech Distributed Electric Propulsion Blown Wing," 15th AIAA Aviation Technology, Integration, and Operations Conference, AIAA Aviation, American Institute of Aeronautics and Astronautics, June 2015, AIAA 2015-3188.

${ }^{5}$ Fredericks, W. J., Moore, M. D., and Busan, R. C., "Benefits of Hybrid-Electric Propulsion to Achieve 4x Cruise Efficiency for a VTOL UAV," 2013 International Powered Lift Conference, AIAA Aviation, American Institute of Aeronautics and Astronautics, Aug. 2013.

${ }^{6}$ Stemme AG, "S10," http://www.stemme.com/s10.html, 2016, accessed 18 Oct 2016.

${ }^{7}$ Alisport Srl, "Silent 2 Electro: Electric Self-Launch Sailplane FAI CLASS 13.5m," http://www.alisport.com/eu/eng/silent2electro.htm, accessed 18 Oct 2016.

${ }^{8}$ Graupner, "CAM Folding Propeller with Spinner 5 x $2.4(12 \times 6 \mathrm{~cm})$," https://www.graupnerusa.com/Electric-sailplanefolding-propeller-with-spinner-1335.12.6.html, Accessed 4-10-2017.

${ }^{9}$ Barrell, E., "Folding and Feathering Propeller Test," Yachting Monthly, 24 March 2015, http://www.yachtingmonthly.com/gear/folding-and-feathering-propeller-test-29807, accessed 18 Oct 2016.

${ }^{10}$ Greenwood, D. T., Principles of Dynamics, chap. 7: Basic Concepts and Kinematics of Rigid Body Motion, Prentice Hall, 2nd ed., 1988.

${ }^{11}$ Durand, W. F., Aerodynamic Theory, Springer Berlin Heidelberg, 1935, pp. 169-360.

12 "OpenVSP," www.openvsp.org, Accessed 02-15-2017.

${ }^{13}$ Patterson, M. D., Borer, N. K., and German, B., "A Simple Method for High-Lift Propeller Conceptual Design," $54 t h$ AIAA Aerospace Sciences Meeting, AIAA SciTech, American Institute of Aeronautics and Astronautics, Jan. 2016, AIAA 2016-0770.

${ }^{14}$ Nichols, R., Tramel, R., and Buning, P., "Solver and Turbulence Model Upgrades to OVERFLOW 2 for Unsteady and High-Speed Applications," 24th AIAA Applied Aerodynamics Conference, Fluid Dynamics and Co-located Conferences, San Francisco, CA, June 5-8 2006, AIAA 2006-2824.

${ }^{15}$ Nichols, R. and Buning, P., User's Manual for OVERFLOW 2.2, NASA Langley Research Center, Hampton, VA, August 2010.

${ }^{16}$ Henrick, A. K., Aslam, T. D., and Powers, J. M., "Mapped weighted essentially non-oscillatory schemes: Achieving optimal order near critical points," Journal of Computational Physics, Vol. 207, No. 2, Aug. 2005, pp. 542-567.

${ }^{17}$ Tramel, R., Nichols, R., and Buning, P., "Addition of Improved Shock-Capturing Schemes to OVERFLOW 2.1," 19th AIAA Computational Fluid Dynamics, Fluid Dynamics and Co-located Conferences, American Institute of Aeronautics and Astronautics, June 2009, AIAA 2009-3988.

${ }^{18}$ Shur, M. L., Strelets, M. K., Travin, A. K., and Spalart, P. R., "Turbulence Modeling in Rotating and Curved Channels: Assessing the Spalart-Shur Correction," AIAA Journal, Vol. 38, No. 5, May 2000, pp. 784-792.

${ }^{19}$ Menter, F. R., "Two-equation eddy-viscosity turbulence models for engineering applications," AIAA Journal, Vol. 32, No. 8, Aug. 1994, pp. 1598-1605.

${ }^{20}$ Langtry, R. and Menter, F., "Transition Modeling for General CFD Applications in Aeronautics," 43rd AIAA Aerospace Sciences Meeting and Exhibit, Aerospace Sciences Meetings, American Institute of Aeronautics and Astronautics, Jan. 2005. 